\title{
装配式建筑施工技术在建筑工程施工管理中的应用研究
}

\author{
王殿涛 李佰西 \\ 中国二十冶集团有限公司，上海 201900
}

[摘要]近年来, 我国加大了改革开放的力度, 从而有效的推动了整个社会经济水平的显著提升, 为各个领域的发展壮大带来 了诸多的机遇，促进了民众生活水平的提升。在这种发展形势下，人们对于生活环境提出了更高的要求，这样就对建筑工程 行业的发展起到了积极的推动作用。装配式建筑施工技术与以往老旧的现浇建筑工程相对比来说, 不但可以有效的提升工程 的施工效率, 并且还可以促进各类施工资源的利用效率的提升, 所以在建筑工程行业中, 应当大范围的推进装配式建筑施工 技术的运用，带动建筑工程行业的持续健康发展。

[关键词]装配式建筑; 施工管理; 施工技术; 应用措施

DOI：10.33142/ec.v3i12.2946 中图分类号：TU741 文献标识码：A

\section{Application of Prefabricated Building Construction Technology in Construction Management of Construction Engineering}

WANG Diantao, LI Baixi

China MCC 20 Group Co., Ltd., Shanghai, 201900, China

\begin{abstract}
In recent years, China has increased the intensity of reform and opening up, which effectively promoted the significant improvement of the whole social and economic level, brought many opportunities for the development of various fields, and promoted the improvement of people's living standards. In this way, the construction industry plays a positive role in the development of the environment. Compared with the old cast-in-place construction project, prefabricated construction technology can not only effectively improve the construction efficiency of the project, but also promote the utilization efficiency of various construction resources. Therefore, in the construction industry, we should promote the application of prefabricated construction technology in a large range, so as to promote the sustainable and healthy development of the construction industry.
\end{abstract}

Keywords: prefabricated building; construction management; construction technology; application measures

\section{引言}

装配式建筑施工技术是社会发展的必然产物, 是当前建筑工程行业中最为新型的一种施工模式, 装配式建筑施工 技术具备良好的优越性, 将这项施工技术合理的运用到建筑工程施工工作之中, 能够有效的提升各类工程资源的利用 效率, 鉴于此, 这篇文章主要针对装配式建筑施工技术在建筑工程施工管理工作中的实践运用展开全面深入的研究分 析, 希望能够对我国建筑工程行业的持续稳定发展有所帮助。

\section{1 装配式建筑施工技术的应用优势}

就建筑工程管理工作来说, 装配式建筑施工技术所具有的最为突出的优越性主要集中在下面几个方面：首先，能 够从根本上促进建筑工程施工质量的提升。在装配式建筑工程中, 各个结构部件通常都是在工厂内生产完成的, 这样 就能够从根本上解决以往老旧的产品质量问题。通常情况下, 利用装配式的方式来取代人工操作方式, 能够有效的规 避施工失误情况的发生, 保证工程施工整体质量。其次, 管理模式的创新。就装配式建筑模式来说, 能够切实的展现 出生产工厂化和设计标准化的特征, 从各个细节入手提升生产工序的完善性, 从而促进工作效率的提升。再有, 增强 管理工作的效果。在将装配式建筑施工技术加以实践运用之后, 湿作业的工作量会逐渐的减少。其次, 就实践交叉作 业落实情况来说, 生产效率的提高显现出了巨大的重要作用, 并且对于推动建筑工程行业的良好发展也起到了积极的 辅助作用 ${ }^{[1]}$ 。

\section{2 装配式建筑项目全过程管理的基本需求}

（1）在装配式建筑项目全过程管理机制之中，策划决策是工作的核心。当下，我国还没有针对装配式建筑项目管 理目标加以设定, 各个地区在落实管理工作的过程中存在明显的差别, 针对这个问题, 工作人员需要形成良好的管控 意识, 从多个角度对项目进行策划。 
（2）在实际开展规划设计工作的过程中, 需要综合各方面实际情况和需要制定完善的施工计划。要想从根本上促 进建筑工程项目管理工作整体水平和效率的提升, 那么最为关键的就是需要对工程设计方案的切实性和高效性加以保 证。但是就现如今我国实际情况来说, 在上述工作方面存在明显的经验不足的问题, 所以需要组建专业的全过程管理 团队, 针对设计方案加以专业分析研究 ${ }^{[2]}$ 。

（3）要想切实的对建筑项目各项工作的有序高效开展加以保证，那么最为有效的方法就是对项目质量和安全进行 全面的控制。就我国装配式建筑实际情况来说, 整体水平还没有达到成熟的状态, 所有环节管理工作还需要加以切实 的优化, 尤其是对施工质量的管控工作, 需要给予重点关注。在组织开展施工工作的过程中, 对于所有运送到施工现 场的结构部件都需要进行严格的检查, 在保证无误的情况下方能加以使用。

(4) 运用装配式建筑项目不但可以保证前序与后序施工工作的良好统一性, 并且还能确保装饰装修工程与施工工 作同步开展。所以在组织实践施工工作的时候, 往往会出现交叉施工的情况, 再加上施工工作会受到多方面因素的影 响, 所以极易引发工程施工质量和施工安全问题。为了促进工程施工效率的提升, 可以利用分段验收的方法, 从不同 的角度入手来提高验收工作的整体效率 ${ }^{[3]}$ 。

\section{3 装配式结建筑及其分类}

\section{1 装配式结构建筑}

装配式结构建筑其实质是在正式开始建筑施工工作之前, 将建筑结构部件在生产厂房内完成统一生产制造, 随后 将生产出来的结构部件运送到施工现场进行组装, 最后形成完整的建筑工程结构。装配式建筑结构部件的预制地点十 分的灵活, 可以式建筑工程也可以是其他预制地点, 在挑选预制地点的时候, 应当秉承因地制宜的原则, 这样就能够 有效的对预制部件的运输成本加以控制。

\section{2 装配式建筑类型}

（1）全装配式建筑。这种类型的建筑装配式程度最高, 通常所有的结构部件都是在工厂内统一生产完成的, 就如 同机械生产模式一样。建筑结构部件实现产品化, 将所有的结构部件在工厂内完成统一生产, 随后将结构部件运送到 工程施工现场进行组装，这种建筑模式能够切实的提升施工工作的效率，最大限度的避免施工质量问题的发生。

（2）半装配式建筑。这种装配式建筑与全装配式建筑结构相对比来说，装配程度相对较低，只有部分建筑结构部 件会运用预制的方式进行生产，其余结构部件都是采用的现场砌筑的方式。班装配式建筑对于生产基地的投入要求相 对较低, 可以有效的实现控制运输成本的目的, 具有良好的经济性 ${ }^{[4]}$ 。

\section{4 装配式建筑施工技术应用的注意事项}

\section{1 做好工程设计质量的把控}

要想将装配式建筑施工技术所具有的优越性充分的发挥出来, 那么还需要对工程设计工作加以重点关注。工作人 员在进行结构部件的制造工作之前, 需要将设计标准与施工图充分结合在一起, 促进建筑结构部件设计方案整体效果 的提升, 并且还能够为后续工程设计工作的实施给予良好的协助。其次, 所有的设计工作人员需要对各个分支结构部 件连接质量加以全面的把控，保证实现既定的施工管理目标。

\section{2 注重 BIM 技术的应用}

就现如今实际情况来说, 在建筑工程施工管理信息化和智能化水平的不断提升的带动下, 有效的推动了建筑工程 管理工作效率和质量的提升。经过大量的实践调查我们发现, 将 BIM 技术加以实践运用, 对于保证工程施工质量和施 工效率方面起到了积极的影响, 这项技术的运用主要集中在下面几个方面: 第一, 质量管理。装配式建筑施工工作对 于专业施工技术的要求相对较高, 特别是在生产质量方面表现的更加突出。在 BIM 技术的辅助下, 能够合理的利用碰 撞试验来对施工工作进行模拟, 从而促使施工工作人员能够对管道线路的安设情况加以全面掌握, 从而对后续各项工 作的实施进行合理的安排 ${ }^{[5]}$ 。第二, 进度管理。建筑工程施工进度管理工作在整个建筑管理工作中的作用是非常巨大的, 在保证装配式建筑施工技术得到合理运用的基础上, 将 BIM 技术在施工进度管理工作中所具有的重要影响作用展现出 来，对各项影响因素加以切实的把控。

\section{5 装配式建筑施工技术在建筑工程施工管理中的应用}

\section{1 构件堆放管理}

在实际组织开展建筑工程施工工作的过程中, 切实合理的运用建筑施工技术, 能够有效提升各项工作的效率和效 
果。因为装配式建筑施工工作具有一定的特殊性, 所以在针对施工材料进行管理工作的时候, 务必要对各个结构部件 的存放加以合理的管控。并且要充分结合结构部件的特征, 利用有效的防护措施对结构部件的质量加以保证, 避免在 将结构部件进行堆放和运输的过程中出现结构破损的情况。其次, 如果发现建筑结构部件存在破损的问题的时候, 需 要第一时间进行修复或者是调换, 避免将破损的结构部件运用到建筑施工工作之中。在进行建筑结构部件存放工作的 时候, 不得不说的是, 要结合种类的不同进行分类存放, 并且在结构部件底层需要设置垫层, 切实的保证结构部件的 整体质量 ${ }^{[6]}$ 。

\section{2 施工管理}

在组织实施装配式建筑工程各项施工工作的过程中, 往往会遇到诸多的突发情况, 所以需要针对各项施工工作加 以切实的管控。第一, 需要对各个结构部件质量加以严格的检核, 一旦发现任何的异常情况, 都需要与生产方取得联 系, 进行调换, 只有保证结构部件质量达到规定要求的情况下方能加以运用。第二, 针对施工人员施工工作的开展继 续宁全面的监督管控, 确保各项施工工作按照既定的计划有序的开展。第三, 组建专门的检查小组, 借助专业的监测 技术对施工质量进行监测。在落实各项管理工作的时候, 需要对工作进行详细的记录, 并且进行保存, 为后续维保工 作的实施提供参考。

\section{3 构配件场内运输}

第一, 在进行建筑结构部件运输工作的时候, 需要对结构部件做好切实的防护工作, 避免在运输过程中出现任何 的部件破损的情况。第二, 对于结构部件运输线路需要加以合理的设计, 确保结构部件在运输过程中的安全性。第三, 需要挑选专业水平较高的工作人员, 推动各项工作高效高质的开展。

\section{4 预制构件的安装工艺}

在对预制构件进行安装时, 首先安装人员应该校正安装位置、标高、垂直度等要素。在对水平构件进行安装时还 应该校对不同相邻构件之间的平整度和高度差, 保证水平构件在一个水平面上, 做好上述校对后, 对预制构件进行临 时固定。对于坚向预制构件的安装, 要保证首层支撑架体的地基有一定的坚实性和平整性, 上下层架体要对准, 整个 结构要保证与设计保持一致性, 这样才能保证建筑结构支撑系统的安全稳定性, 确保建筑结构整体质量。

\section{6 结束语}

总的来说, 装配式建筑施工模式的运用切实的促进了整个建筑工程行业的持续健康发展, 并且也提升了各类施工 资源的利用效率, 对于整个人类社会的和谐健康发展起到了良好的推动作用。

\section{[参考文献]}

[1]朱习飞. 装配式建筑施工技术在建筑工程施工管理中的应用 [J]. 住宅与房地产, 2020(21): 135 .

[2]张成瑞. 装配式建筑施工技术在建筑工程施工管理中的运用 $[\mathrm{J}]$. 城市建设理论研究 (电子版), 2020(17): 42-43.

[3]陈云. 装配式建筑施工技术在建筑工程施工管理中的应用 [J]. 建材与装饰, 2020 (17) : 117-118.

[4] 周遂. 装配式建筑施工技术在建筑工程施工管理中的应用 [J]. 工程建设与设计, 2020 (5): 242-244.

[5]刘婷. 装配式建筑施工技术在建筑工程施工管理中的应用研究 [J].中阿科技论坛 (中英阿文) , 2020 (1) : 27-31.

[6]王敬. 装配式建筑施工技术在建筑工程施工管理中的应用 [J]. 江西建材, 2019 (8): 110-111.

作者简介: 王殿涛 (1976.6-) 男, 毕业于: 哈尔滨工程高等专科学校, 所学专业: 工程测量, 当前就职于: 中国二十 冶集团有限公司, 职务: 项目经理, 职称: 高级工程师; 李伯西(1989.2-) 男, 毕业于: 长沙学院, 专业: 土木工程, 就职于: 中国二十冶集团有限公司, 职务: 项目总工程师, 职称：工程师。 